\title{
Reply to: Cohen and Ross: “Laser-Induced Chrysiasis: A Unique Adverse Event Associated with Q-Switched Lasers"
}

\author{
Tina S. Alster ${ }^{1}\left[\right.$ Monica K. Li ${ }^{2}$ \\ Accepted: 23 January 2021 / Published online: 27 February 2021 \\ (c) The Author(s), under exclusive licence to Springer Nature Switzerland AG part of Springer Nature 2021
}

To the Editor,

We thank Cohen and Ross for their letter "Laser-Induced Chrysiasis: A Unique Adverse Event Associated with Q-Switched Lasers" [1]. While uncommon, this additional complication is worthy of inclusion as a possible undesirable outcome of Q-switched (or other short-pulsed) laser treatments. Chrysiasis is characterized by skin pigmentation due to deposition of gold pigment following long-term chrysotherapy [2]. Certainly, prevention of the phenomenon would be accomplished by obtaining a comprehensive medical history including any lifetime exposure to gold [3]. It is believed that cutaneous pigmentation appears immediately after Q-switched laser therapy due to reduction of the gold particle size [4]. Regrettably, management strategies for this phenomenon are case-based, making its avoidance of paramount importance [3, 5]. We appreciate the authors highlighting this potential untoward outcome and supplementing our collective knowledge of safe laser practices.

\section{Declarations}

Funding No funding was received for the preparation of this letter.

Conflict of interest No conflict exists for either author (T.S. Alster and M.K. Li).

\section{References}

1. Cohen PR, Ross EV. Laser-induced chrysiasis: a unique adverse event associated with Q-Switched lasers. Am J Clin Dermatol. 2021. https://doi.org/10.1007/s40257-021-00589-5.

2. Kwon WJ, Lee MK, Cho HS, et al. Suspicious case with laserinduced chrysiasis: hyperpigmentation following laser toning with neodymium:yttrium-aluminum-garnet in a woman previously treated with microneedle therapy system using gold. J Dermatol. 2017;44(8):978-9.

3. Cohen PR, Ross EV. Q-switched alexandrite laser-induced chrysiasis. J Clin Aesthet Dermatol. 2015;8(9):48-53.

4. Trotter MJ, Tron VA, Hollingdale J, Rivers JK. Localized chrysiasis induced by laser therapy [observation]. Arch Dermatol. 1995;131:1411-4.

5. Yun PL, Arndt KA, Anderson RR. Q-switched laser-induced chrysiasis treated with long-pulsed laser [the cutting edge]. Arch Dermatol. 2002;138:1012-4.

This reply refers to the comment available at: https://doi. org/10.1007/s40257-021-00588-6.

This reply refers to the article available at: https://doi.org/10.1007/ s40257-020-00530-2.

Tina S. Alster

talster@skinlaser.com

1 Washington Institute of Dermatologic Laser Surgery, Washington, DC, USA

2 City Medical Aesthetics Center, Vancouver, BC, USA 